\title{
Why Thirlwall's law is not a tautology: more on the debate over the law
}

\author{
J.S.L. McCombie* \\ University of Cambridge, UK
}

This paper reconsiders the argument first debated in the 1980s and revisited by Blecker (2016) and Razmi (2016), inter alios, that Thirlwall's law is nothing but a near-identity. It is shown theoretically and by simulation analysis that this proposition is erroneous. It is also demonstrated that Razmi's (2016) specification of the balance-of-payments-constrained growth model is problematical. The paper concludes by assessing the effectiveness of the rate of change of relative prices for export and import growth. Recent evidence provides further support for the importance of non-price competitiveness in international trade and, hence, for Thirlwall's law.

Keywords: Thirlwall's law, balance-of-payments-constrained growth, tautology, price and non-price competitiveness

JEL codes: E12, F32, F43

\section{INTRODUCTION}

Thirlwall's law (1979) is now 40 years old and since the publication of the seminal article there have been numerous papers both confirming Thirlwall's law and extending it theoretically and empirically. When Thirlwall's paper was first published there were a number of early criticisms and lively debates. One was concerned with whether or not the law is merely a tautology (McCombie 1981; Thirlwall 1981; McCombie 2011). The outcome of the debate is that the criticism is invalid: the law is not a tautology. However, ironically, the same argument criticizing the law has recently been put forward again. See, inter alios, Blecker (2016) and Razmi (2016).

This paper first shows that the earlier conclusion that the criticism is untenable is confirmed with respect to Blecker's restatement of it. It is further shown that Razmi's reformulation of Thirlwall's model suffers from a number of problems. The paper concludes with an assessment of the effectiveness of changes in relative prices with respect to Thirlwall's law.

\section{THIRLWALL'S LAW IS NOT A TAUTOLOGY}

The standard test of Thirlwall's law, which goes back to Thirlwall's (1979) seminal paper, is to test the closeness of the fit between $y_{b}=\left(\frac{\hat{\varepsilon}}{\tilde{\pi}}\right) w$ and $y$, where $y_{b}$ is the

* I am grateful to Jesus Felipe, Rafael Ribeiro, João Romero, Tony Thirlwall and a referee for their helpful comments. The usual disclaimer applies. 
balance-of-payments-constrained growth rate of income, $y$ is the actual rate of growth and $w$ is the growth of world income. $\hat{\varepsilon}$ and $\hat{\pi}$ are the econometric estimates of the income elasticities of demand for exports and imports respectively. They are the values derived from the estimation of the standard macroeconomic export and import demand functions. These regressions include a relative price term and normally use annual data. $w$ and $y$ used in the test mentioned above are the average exponential growth rates of world and domestic income respectively, calculated using the terminal and initial level figures of the period. The law is considered to be not refuted if the estimate of $y_{b}$ is sufficiently close to $y$. A corollary of this test is that the estimated income elasticities should both be statistically significant. (See Thirlwall 2011 for a history of the development of the law.)

However, Blecker (2016, p. 276) claims that 'in recent years a number of heterodox critics ... have questioned both the theoretical logic of Thirlwall's law and the empirical evidence in its favour'. He contends that 'tests of Thirlwall's law are testing a nearidentity that is likely to be satisfied for almost any country regardless of whether its growth is BP- [balance-of-payments] constrained in the sense of Thirlwall or not' (ibid., p. 277). The implication is that the law is likely to be confirmed for any data set where the "the quantities of exports and imports grow at approximately the same rate in the long run' (ibid., p. 277). Razmi (2016) takes a similar view, concluding that the "the traditional approach to testing the BPCG [balance-of-payments-constrained growth] model is really a test of whether or not exports and imports grow at similar rates' (ibid., p. 1585). ${ }^{1}$ Razmi assumes that changes in relative prices are negligibly small. We return to this point below. Consequently, Blecker terms Thirlwall's law a 'near-tautology' or 'near-identity'.

However, in this section, which is an elaboration of the argument in Thirlwall (1981) and McCombie (1981; 2011, sec. 2), we show that the error is entirely on the part of the current critics. They have made the mistake of assuming that the mathematical calculation of a total income elasticity, using the long-run average growth rates, must give a value that is always the same (or nearly the same) as the value of the statistical estimation of that coefficient. It does not.

We concentrate on the argument espoused by Blecker (2016), who follows Clavijo Cortes and Ros Bosch (2015), and show that it rests on a fundamental confusion between the mathematical calculation of an elasticity and its econometric estimation. Of course, the principle of testing and determining whether or not relationships in economics are statistically significant is the whole rationale for econometric analysis. Regression coefficients are statistically estimated and not merely arithmetically (or deterministically) calculated from the data. We will show that the failure to make this important distinction is the reason why it is erroneous to assume that Thirlwall's law is a near-identity.

To see this, let us consider Blecker's argument about the law being a tautology. For reasons of generality, we confine ourselves to discussing what is known as the 'strong version' of Thirlwall's law. As we have seen, Thirlwall's law is given by:

$$
y_{b}=\left(\frac{\varepsilon}{\pi}\right) w .
$$

1. In the monetary approach to the balance of payments, the law of one price is assumed to hold, the growth of exports equals imports (which is ultimately determined by the growth of base money) and output is at its maximum potential (Frenkel and Mussa 1985). This is the antithesis of Thirlwall's approach. It shows that whereas the equality of the growth of imports and the growth of exports is a necessary condition for Thirlwall's law to hold, it is not a sufficient condition. 
Blecker's argument that the law is merely a tautology is based on using the calculated (not statistically estimated) values of $\varepsilon$ and $\pi$, namely, $\varepsilon^{*}=x / w$ and $\pi^{*}=m / y . x$ and $m$ are the growth rates of exports and imports. $x, m, w$ and $y$ are the average exponential growth rates calculated over a period of years. In other words, for example, $x=(1 / T)\left(\ln X_{T}-\ln X_{0}\right)$, where $X$ is the level of exports and $T$ is the length of the period in years and the subscripts $T$ and 0 denote the terminal and base year.

Substitution of these two equations for $\varepsilon^{*}$ and $\pi^{*}$ into equation (1) and rearranging gives:

$$
y_{b} \equiv \frac{x}{m} y .
$$

Hence, the assertion is that, so long as $x=m$, Thirlwall's law is unambiguously a tautology, namely, $y_{b} \equiv y$.

Blecker seeks to justify this result by arguing that:

According to the near-tautology (or near-identity) argument, the econometric estimates of $[\hat{\varepsilon}]$ and $[\hat{\pi}]$ are likely to approximate the ratios of the growth rates of each trade variable (the volume of exports and imports) to the corresponding income growth rate (foreign or domestic), that is, $\left[\hat{\varepsilon} \approx \frac{x}{w}\right]$ and $\left[\hat{\pi} \approx \frac{m}{y}\right] \ldots-$ especially if relative price effects are negligible in the long run. (Blecker 2016, p. 277, emphasis added)

Blecker (2016, p. 278) concedes that the inclusion of the relative price term means the law is not an identity. Nevertheless he argues that, as a matter of logic, 'if relative prices are small or insignificant, then the estimated income elasticities should be closer to the observed ratios $[x / w]$ and $[\mathrm{m} / \mathrm{y}]$ than if relative prices were large and significant' (ibid., p. 278, emphasis in the original). Hence, this is seen as reinforcing the argument that Thirlwall's law is a 'near identity'.

However, there is no econometric reason why, in a regression of a variable on (say) two regressors, if one regressor is statistically insignificant, this will necessarily make the other regressor better-determined or will significantly affect its estimated value.

The fundamental flaw in the argument that Thirlwall's law is a near-identity, even if changes in relative prices are statistically insignificant, is that there is nothing in econometric theory that necessarily implies $\varepsilon^{*} \approx \hat{\varepsilon}$ and $\pi^{*} \approx \hat{\pi}$. Whether or not they do is an empirical matter. $\varepsilon^{*}$ and $\pi^{*}$ are both derived from a deterministic calculation based on two data points and there is no error term. It is also a calculation of a total, rather than a partial, elasticity.

Consequently, for a given $x, w$ and $y$, there is a precise value of $\varepsilon^{*} . \hat{\varepsilon}$, however, is an estimated partial elasticity using numerous observations. There is no reason why it should not be statistically significantly different from $\varepsilon^{*}$ or indeed from zero, at the chosen confidence level. To put this another way, there is no a priori reason, for example, why $\varepsilon^{*} \approx \hat{\varepsilon}$. The reason why this may be likely to occur is because the results of the estimation of the export and import demand functions empirically confirm Thirlwall's law. There is no logical reason why $\varepsilon^{*}$ and $\hat{\varepsilon}$ (or $\pi^{*}$ and $\hat{\pi}$ ) should be approximately equal. It is an empirical issue.

2. Blecker argues that if the relative price term is endogenous, its estimated coefficient may be biased downwards. Romero and McCombie (2016; 2018) and Christodoulopoulou and Tkačevs (2016) control for simultaneity and find that the relative price term is quantitively unimportant and/or statistically insignificant for a wide range of developed countries. 
We may see this, at the risk of some repetition, by further considering the argument. The supposed tautological nature of Thirlwall's law stems from the use of the numerical calculations of export and import income elasticities calculated using only data at the end and beginning of the period. Consequently,

$$
\varepsilon^{*} \equiv \frac{\ln \left(X_{T} / X_{0}\right) / T}{\ln \left(W_{T} / W_{0}\right) / T} \equiv \frac{x}{w},
$$

where $W$ is the level of world income.

It will be recalled that the star on the elasticities serves to remind us that this estimate is an arithmetical value and not an estimated value, which, as above, we denote by $\hat{\varepsilon}$.

The same argument applies to the income elasticity of demand for imports

$$
\pi^{*} \equiv \frac{\ln \left(M_{T} / M_{0}\right) / T}{\ln \left(Y_{T} / Y_{0}\right) / T} \equiv \frac{m}{y},
$$

where $M$ and $Y$ are the levels of imports and domestic income.

Thirlwall's law, as we have seen, according to Blecker's argument, is given by the equation:

$$
y_{b}^{*} \equiv \frac{\varepsilon^{*}}{\pi^{*}} w \equiv y
$$

where $y_{b}^{*}$ is the balance-of-payments-constrained growth rate using the mathematically calculated elasticities.

Thus, if we substitute equations (3) and (4) into (5), we do indeed derive a quasiidentity because of the way $\varepsilon^{*}$ and $\pi^{*}$ have been calculated, namely:

$$
y_{b}^{*} \equiv \frac{x / w}{m / y} w \equiv y .
$$

This derivation is, as Blecker correctly notes, a tautology provided that the growth of $x$ and $m$, mathematically calculated over the long run, are equal, which empirically holds for many countries.

However, in practice, the estimates of the elasticities are obtained by estimating the following equations, in their simplest form:

$$
\ln X_{t}=c_{1}+b_{1} \ln W_{t}+b_{2} \ln P_{t}+\mu_{t}
$$

and

$$
\ln M_{t}=c_{2}+b_{3} \ln Y_{t}+b_{4} P_{t}^{\prime}+\varphi_{t}
$$

where $P_{t}$ and $P_{t}^{\prime}$ are the appropriately defined relative price terms. $\mu_{t}$ and $\varphi_{t}$ are the error terms and $c_{1}$ and $c_{2}$ are constants. ${ }^{3}$ The subscript $t$ denotes the year and we assume, for comparability with equations (1) and (2), that $t$ runs from the base year to $T$.

3. The seminal empirical papers of Houthakker and Magee (1969) and Goldstein and Khan (1978) omit the time trend. The autonomous growth of exports and imports of the various countries are captured in the (differing) estimates of the respective income elasticities of demand. 
The econometric and consequently correct test of Thirlwall's law is whether or not

$y_{b}=\frac{\hat{\varepsilon}}{\hat{\pi}} w$ closely approximates to $y$, and $\hat{\varepsilon}$ and $\hat{\pi}$ are both statistically significant. In this test, $w$ and $y$ are again the long-run exponentially calculated growth rates of world and domestic income.

We are now in a position easily to see the problem with Blecker's argument. Blecker uses the calculated values of the elasticities, whereas the correct test is to use the econometric estimates of the partial elasticities, the values for which we have no $a$ priori information. For Blecker's tautological argument to have any meaning it is necessary for $\varepsilon^{*}$ and $\pi^{*}$ not just to be empirically the same as $\hat{\varepsilon}$ and $\hat{\pi}$ respectively, but for these equalities to be due to a definitional relationship.

Suppose we estimate equation (7). There is nothing in econometric theory that states that, using the same data set, the estimate of $\hat{\varepsilon}$ should be equal to $\varepsilon^{*}$. The same is true for equation (8). They are not identities. There is no a priori reason why $\hat{\varepsilon} / \hat{\pi}$ should equal $\varepsilon^{*} / \pi^{*}$.

One reason why the estimates of the income elasticities could be statistically insignificant is that the variance of the logarithm of exports (or imports) is almost completely explained by the logarithm of the relative price term; for example, the Neoclassical law of one price empirically holds. In this case, the estimates of the income elasticities are likely to be statistically insignificant. There is no necessary reason why the estimated income elasticities should always be statistically significant. Thirlwall (1981) made this point nearly 40 years ago.

The issue is actually more general than this. There is no econometric reason why the estimated coefficients in a regression equation should not all be statistically insignificant. After all, they are derived from behavioural relationships and this is why elasticities are estimated econometrically and not simply calculated arithmetically.

As has been shown, the argument that Thirlwall's law is simply a tautology is based on a confusion between a statistically estimated elasticity and an arithmetically calculated one. In order to illustrate this argument, we estimated some export and import demand functions in a simulation analysis.

\section{THIRLWALL'S LAW AND A SIMULATION EXERCISE}

It should be emphasized that the simulations have no implications as to whether or not Thirlwall's law actually empirically holds. But what they do show is that the issue is an empirical, and not a tautological, one. This is in spite of the fact that in all the simulation exercises we impose the condition that, over the period of the data set, the average growth rates of exports and imports are exactly equal. It will be recalled that, according to Blecker, inter alios, this relationship is all that is necessary to ensure that Thirlwall's law is a tautology.

We report the results of only five regressions of export and import demand functions out of the many that have been run, but they all have the same implications for the theoretical argument.

The various five simulation databases consist of annual indices of the volumes of imports, exports, world income domestic income and relative prices. The data consist of ten years' annual observations. ${ }^{4}$ The long-run average growth of world income and domestic income were set equal to 3 per cent per annum in all the databases.

4. We ran other simulations with 20 and 30 observations. Our argument, though, is not dependent on the sample size. 
These specific figures do not have any significant role to play in the argument and we could equally have used any values. But what does matter is the fact that the long-run growth of imports and exports are constrained to be equal and average 6 per cent per annum. The data were constructed so that the volume of exports equals the volume of imports at the beginning of the sample, and there is no long-term growth of capital flows.

From all five databases, the numerical calculation of the elasticities is $\varepsilon^{*} \equiv 6 \% / 3 \%=2$ and $\pi^{*} \equiv 6 \% / 3 \%=2$. These equalities consequently hold for all the simulations, although the annual observations of the variables differ between the databases. Nothing depends on the particular values of the elasticities.

Thirlwall's law, using this numerical method, is given by $y_{b} \equiv \varepsilon^{*} w / \pi^{*}=3 \%$ per year, which, given the way it is calculated, is indeed a tautology. However, the whole point of obtaining statistical values for the income elasticities of export and import demand functions, since Houthakker and Magee (1969), is to determine whether or not the estimates are statistically significant and what predictive power they have.

Consequently, we estimated the export and import demand functions using the very different annual values from the five simulation databases. We obtain the results reported in Table 1. Equations 1(a) and 1(b) refer to the results using database 1, equations 2(a) and (2b) using database 2, etc. Table 2 reports a summary of the elasticities and the calculation of Thirlwall's law. The results are based on the use of ordinary least squares regression analysis. As the point we are making is about the difference in effect of using statistical estimates of the elasticities, per se, compared with their numerical calculation, the exact method of estimation is unimportant. Hence, we also do not report the usual regression diagnostic tests.

As the estimation of the various coefficients is an econometric matter, it is not possible to predict the values of the coefficients a priori. Using database 1, the results are given by equations 1 (a) and 1(b) and the estimated coefficients of both $\ln W$ (that is, $\hat{\varepsilon}$ ) and $\ln Y$ (that is, $\hat{\pi}$ ) are statistically insignificant. The variation in the logarithms of exports and imports are statistically significantly explained by variations in the logarithms of the indices of the relative price terms $\left(\ln P\right.$ and $\left.\ln P^{\prime}\right)$ and not by the logarithms of the income terms.

Using databases 2, 3, 4 and 5, the relative price terms are insignificant and, consequently, are dropped from the specifications of the regressions. This has the advantage that we are now comparing the different ways of determining the values for the total, and not partial, income elasticities. Using database 2, the estimate of $\hat{\varepsilon}$ is just significant and $\hat{\pi}$ is statistically at the 95 per cent confidence level. However, using database 3 , the income elasticities are both statistically significant (a necessary, but not sufficient condition, for the non-refutation of Thirlwall's law). Using databases 4 and 5, the elasticities are statistically significant, but their values are very different from $\varepsilon^{*}$ and $\pi^{*}$.

For convenience, these estimates are summarized in Table 2, together with the estimates of $y_{b}$. As the estimates of the import and export functions are independent of each other, we also report Thirlwall's law using the estimates of the income elasticities from equations 1(a) and 3(b) and also 3(a) and 1(b).

It should be noted that equations 1(a) and 3(b) use the export and import statistics from databases 1 and 3 respectively. Similarly, equations 3(a) and 1(b) use the export and import statistics from databases 3 and 1.

It can be seen that Thirlwall's law using $\varepsilon^{*}$ and $\pi^{*}$ in all five databases is not, and cannot, be refuted because of the way that the elasticities are arithmetically calculated. In other words, $y_{b}^{*} \equiv\left(\varepsilon^{*} / \pi^{*}\right) w \equiv y$. Furthermore, in the light of previous discussion, they not surprisingly give identical results for all five databases. This is Blecker's tautology and is not a test of Thirlwall's law. 
Table 1 Estimated export and import demand functions: results using the five databases

\begin{tabular}{|c|c|c|}
\hline 1(a) & $\ln X=\underset{(9.15)}{13.911}+0.191 \ln W-2.205 \ln P$ & $\bar{R}^{2}=0.959$ \\
\hline 1(b) & $\begin{aligned} \ln M= & 13.186+0.248 \ln Y-2.088 \ln P^{\prime} \\
(9.15) \quad(0.89) & (-5.06)\end{aligned}$ & $\bar{R}^{2}=0.828$ \\
\hline 2(a) & $\begin{aligned} \ln X= & 0.129+1.010 \ln W \\
& (0.05) \quad(1.98)\end{aligned}$ & $\bar{R}^{2}=0.245$ \\
\hline 2(b) & $\begin{aligned} \ln M= & 1.342+0.739 \ln M \\
& (0.08) \quad(1.40)\end{aligned}$ & $\bar{R}^{2}=0.197$ \\
\hline 3(a) & $\begin{array}{c}\ln X=-4.437+1.971 \ln W \\
(0.08) \quad(27.39)\end{array}$ & $\bar{R}^{2}=0.989$ \\
\hline 3(b) & $\begin{aligned} \ln M= & -3.886+1.845 \ln Y \\
& (-6.92) \quad(15.69)\end{aligned}$ & $\bar{R}^{2}=0.968$ \\
\hline 4(a) & $\begin{aligned} \ln X= & -0.495+1.117 \ln W \\
& (-0.25) \quad(2.65)\end{aligned}$ & $\bar{R}^{2}=0.467$ \\
\hline 4(b) & $\begin{aligned} \ln M= & 0.034+1.001 \ln Y \\
& (0.03) \quad(4.13)\end{aligned}$ & $\bar{R}^{2}=0.680$ \\
\hline 5(a) & $\begin{aligned} \ln X= & 0.741+0.861 \ln W \\
& (0.35) \quad(1.97)\end{aligned}$ & $\bar{R}^{2}=0.243$ \\
\hline 5 (b) & $\begin{aligned} \ln M= & -3.836+1.851 \ln Y \\
& (-3.43) \quad(7.86)\end{aligned}$ & $\bar{R}^{2}=0.871$ \\
\hline
\end{tabular}

Notes: In all regressions the long-run growth of exports equals the growth of imports and is 6 per cent per annum. The long-run growth of world and domestic income equals 3 per cent per annum. The values of cumulative imports equal cumulative exports over the period. The annual values of exports and imports differ between the databases. Figures in parentheses are $t$-values.

Table 2 Income elasticities and Thirlwall's law

\begin{tabular}{lccccccc}
\hline Equations & $\hat{\varepsilon}$ & $\hat{\pi}$ & $\tilde{y}_{b}$ & $\varepsilon^{*}$ & $\pi^{*}$ & $y_{b}^{*}$ & $y$ \\
\hline 1(a) and 1(b) & $0.191^{\S}$ & $0.248^{\S}$ & 2.310 & 2.0 & 2.0 & 3.0 & 3.0 \\
2(a) and 2(b) & $1.010^{\#}$ & $0.739^{\S}$ & 4.100 & 2.0 & 2.0 & 3.0 & 3.0 \\
3(a) and 3(b) & $1.971^{\#}$ & $1.845^{\#}$ & 3.205 & 2.0 & 2.0 & 3.0 & 3.0 \\
4(a) and 4(b) & $1.117^{\#}$ & $1.001^{\#}$ & 3.348 & 2.0 & 2.0 & 3.0 & 3.0 \\
5(a) and 5(b) & $0.861^{\#}$ & $1.851^{\#}$ & 1.395 & 2.0 & 2.0 & 3.0 & 3.0 \\
1(a) and 3(b) & $0.191^{\S}$ & $1.845^{\#}$ & 0.311 & 2.0 & 2.0 & 3.0 & 3.0 \\
3(a) and 1(b) & $1.971^{\#}$ & $0.248^{\S}$ & 23.843 & 2.0 & 2.0 & 3.0 & 3.0 \\
\hline
\end{tabular}

Notes: $\S$ denotes the estimated coefficient is not significant at the 95 per cent confidence level and \# that it is. $\widetilde{y}_{b}$ is the output growth calculated from estimate income elasticities of the export and import demand functions. $y_{b}^{*}$ is the predicted output growth from the tautology and $y$ is the actual growth of output.

In four of the databases the calculated income elasticities are not even close to the estimated values. These are the estimates of databases 1,2, 4 and 5 reported in Table 1. Thirlwall's law is refuted in databases 1 and 2 where one of the values of the elasticities is statistically insignificant. This is true for the combinations of equations 1(a) and 3(b) as well as 3(a) and 1(b). This is not the case for database 3 where the 
estimated income elasticities are very close to the arithmetically calculated ones. But there is nothing that ensures, a priori, this must be the case. Database 4 is an interesting case because Thirlwall's law is not refuted even though the values of $\hat{\varepsilon}$ and $\hat{\pi}$ are not close to $\varepsilon^{*}$ and $\pi^{*}$. This is because the ratio of the estimated elasticities is close to the ratio of the calculated one. The regressions using database 5 give estimates of both export and import elasticities that are statistically significant but give a value of $\widetilde{y}_{b}$, the estimated balance-of-payments equilibrium growth rate that is very different from the actual growth rate, $y$.

These various estimates, of course, do not have any implications for the actual estimates of Thirlwall's law. They are merely designed to demonstrate that the law is not a tautology. The empirical testing of the law usually confirms the law, but can in principle refute it. The tautology, by definition, must always confirm it, but this should not be confused with the results of the regressions that also confirm the law. The latter results are not because of the tautology.

\section{SOME PROBLEMS WITH RAZMI'S (2016) MODEL}

As a result the erroneous interpretation of Thirlwall's law as a tautology, Razmi (2016) has proposed a theoretical respecification of the balance-of-payments equilibrium growth equation, which explicitly incorporates the supply side. The revised theoretical equation for the balance-of-payments equilibrium growth rate is given by a hybrid of demand and supply variables, namely:

$$
y_{b}=\beta_{1} w+\beta_{2} k+\beta_{3} e,
$$

where the $\beta$ coefficients consist of various demand and supply price elasticities of imports and exports, $e$ is the growth of the nominal exchange rate, and $k$ is the exogenous growth of the capital stock of the export sector. (In the subsequent empirical analysis, $k$ is proxied by the growth of the total capital stock.) $w$ is again the exogenous growth of world income. Razmi estimates a specification similar to equation (9) using panel-data and single-equation methods for a number of developed and developing countries. The first generally uses growth rates and the second uses log levels. We shall concentrate on the former. The growth of the nominal exchange rate is excluded from the regressions. The logarithm of Rodrik's (2008) measure of the real exchange-rate undervaluation, ${ }^{5}$ the growth of relative export and import prices and the logarithm of external debt-to-income ratio are also included as control variables. (The equation is similar to Thirlwall's law, but with the growth of the capital stock included as an additional regressor.) Razmi finds that, empirically, the estimated coefficient of $k$ is statistically significant and that of $w$ is often significant, but the size of its coefficient is reduced when $k$ is included. Consequently, the regression results mean that an exogenous increase in the growth of the capital stock, due to, say, an increase in entrepreneurs' 'animal spirits', raises the growth of exports and hence the balance-of-payments equilibrium growth rate. This is holding the

5. This is the divergence of the tradable from the non-tradable exchange rate, adjusted for the Balassa-Samuelson affect. It is not derived from the estimation of import and export demand functions. Rodrik (2008) found that it was only important for the low-income countries. Woodford (2008), Goncalves and Rodrigues (2017) and Ribeiro et al. (2019), inter alios, find little or no support for this result. 
other independent variables constant, notably the relative price terms and the growth of world income. An autonomous increase in the growth of world income, via an induced increase in exports can, in turn, in the model, increase the growth of output, again holding the other regressors constant. These somewhat paradoxical results are derived from the underlying theoretical assumptions of the model.

Razmi's (2016, p. 1593, equ. (9)) theoretical specification of the export-supply function, in dynamic form, is a function of the exogenous growth of the export sector's capital stock, together with the growth of the nominal export price. Hence, the former is treated as autonomous in the specification of the theoretical model. Razmi (p. 1593, fn 19) cites Goldstein and Khan (1985) in support of the inclusion of an exogenous scaling factor, who consider either trend income or trend exports. However, Goldstein and Khan (1985, p. 1060) justify the latter in terms of the assumptions underlying the Lucas New Classical 'surprise' supply function. Furthermore, they explicitly state that they assume that long-run output growth is determined by the supply side. Both assumptions are the antitheses of those underlying the balance-of-payments-constrained growth model.

In the balance-of-payments-constrained growth model, the growth of the flow of export-capital services is more plausibly assumed to be endogenous, determined by the growth of exports. Williamson (1983, p. 153) argues that, in the short run, 'the [exporting] manufacturer sets the price and is pleased to sell everything that is demanded at that price'. Firms keep a planned margin of excess capacity (and inventories) to meet a short-term increase in demand, which, if sustained, is met by increased capacity and capital accumulation. As Lavoie (2014, p. 154) puts it, 'there are good theoretical as well as practical reasons, as well as good strategic and technical ones, to explain why corporations generally aim at operating much below their full capacity'.

In the long run, the Kaldorian approach is that

[i]n the case of industrial activities ('manufactures') the impact effect of exogenous changes in demand will be on production rather than on prices. 'Supply', at any rate long-run supply, is normally in excess of demand - in the sense that producers would be willing to produce more, and to sell more, at the prevailing price (or even at a lower price) in response to an increased flow of orders. (Kaldor 1970, p. 485)

So, in this approach, it is the growth of demand for a country's exports that endogenously determines the growth of capital in the export sector, and not vice versa.

The use of the nominal price by Razmi in the theoretical specification of the exportsupply (and the import-supply) functions is implausible as it implies firms are money illusioned. Goldstein and Khan (1978, p. 276; 1985, p. 1045) state that the correct variable is the price of a country's exports relative to its domestic price. As this increases, it becomes more profitable to export. If the country only produces one good, as Razmi assumes, then the relative price will be unity. Razmi cites Dornbusch (1975) and Isard (1995) as cases where nominal prices are used in the context of the standard derivation of the Marshall-Lerner conditions. But, having done this, both Dornbusch (1975, p. 860) and Isard (1995, p. 95) subsequently criticize the approach for not using relative prices. $^{6}$

6. Razmi (2016, p. 1593, fn 16) states that if the demand for imports and exports are also based on nominal prices, it makes no difference to the model. But this does not solve the problem that relative prices should be used. 
As we have noted, the inclusion of the assumed exogenous growth of the total capital stock as a proxy for the export sector's capital stock is statistically significant in the various regression analyses. But this result does not necessarily provide evidence for the importance, or otherwise, of the supply side. This is because this result will always largely be determined by an underlying accounting identity and so does not necessarily reflect a behavioural relationship. The share of capital in the total value of output is given by $a \equiv K / Y$, where $r$ is the rate of profit, $K$ is the capital stock and $Y$ is output. The growth of output is definitionally equal to $y \equiv\left(g_{r}-g_{a}\right)+k$, where $g_{r}$ and $g_{a}$ are the growth rates of $r$ and $a$. If the share of capital and the rate of profit are approximately constant, which empirically is often the case, a regression of $y$ on $k$ must definitionally give a very close goodness of fit, with a value of the slope coefficient of about unity. (This is one of Kaldor's stylized facts.) Even if $a$ and $r$ do change over time, there is still likely be a close statistical fit between $y$ and $k$ because of the identity. This is true even when $k$ is included in a multivariate regression such as Razmi's estimated model, although its coefficient may differ from unity.

Razmi takes a very different approach to the traditional approach to testing whether or not growth is balance-of-payments-constrained, originated by Thirlwall (1979). The latter is discussed below. Razmi describes equation (9) above as theoretically determining the balance-of-payments equilibrium growth rate, but he uses the actual growth of output as the regressor in his empirical approach. The interpretation of the regression results presumably seems to be that the magnitude of the coefficients of $w$ and $k$ reflects the relative contributions of the demand and supply side to the balance-ofpayments-constrained growth rate. As we noted above, the results of the regression analysis mean that either an increase in the growth of world demand, ceteris paribus, or an increase in growth of the capital stock, holding the other regressors constant, will each independently increase the rate of growth of output. In the light of this, in what sense can this be interpreted as a test of whether or not growth is balance-of-payments-constrained or, alternatively, that the estimating equation is of the balance-of-payments-constrained growth rate? A country can always relax the balance-of-payments constraint (that is, increase the growth of output) in this approach simply by investing more in the export sector. This statistical result occurs because the growth of world income, the rate of change of relative prices and the other regressors are all held constant when considering the impact of the growth of the capital stock on the growth of output in the specification of the multiple regression. Likewise, a growth in world income (demand) in this regression specification can increase the growth of output, holding all the other independent variables constant, including, implausibly, the growth of the capital stock.

In Thirlwall's approach to balance-of-payments-constrained growth, the growth of the export-capital stock is endogenously determined by the growth of demand for exports. This is for the reasons discussed above. In this case, the growth of the capital stock should not appear as a regressor in the estimating equation, as in Razmi's model. As a simplification for expositional reasons, we have essentially the following model. First, the estimate of the balance-of-payments equilibrium growth rate of a country is determined by the growth of world demand, $y_{b}=f_{1}(w)$, calculated using the estimates of the elasticities from the export and import demand functions. As discussed in the next section, it is generally found that the rate of change of relative prices has a negligible effect on the growth of exports and imports and, hence, on $y_{b} . y_{b}$ is then tested to determine whether or not it differs from the actual growth of output, which is a function of the supply-side factors. 
Second, the growth of the export-capital stock is determined by the growth of exports, that is, $k=f_{2}(x)$. It follows that $k$ is also a function of the growth of world income, that is to say, $k=f_{3}(w)$, as $x$ is a function of $w$. The last two equations are different specifications of the export-capital supply function.

Let us assume that $k=f_{3}(w)$ is estimated by regressing $k$ on $w$ and is found to be statistically significant. Consequently, we would expect that $k$ could well be statistically significant if it is erroneously included as a regressor of $y$ in the first equation $\left(y=f_{1}(w)\right)$, as in Razmi's estimating equation. It should be noted that this inclusion is not a problem that can be overcome by the use of instrumental variable techniques, as it is a misspecification issue.

An important extension of the traditional Thirlwall approach is that of Lanzafame (2014). Lanzafame calculates $y_{b}$ for a number of countries and tests whether it differs from the econometrically estimated endogenous natural (or maximum) rate of growth, $y_{n}$. (Lanzafame uses the methodology of León-Ledesma and Thirlwall 2002 to estimate the values of the natural rate of growth.) It proves generally not to differ. He further uses panel Granger causality estimation methods in this approach and finds that there is a unidirectional causality from export growth to output growth. Moreover, $y_{n}$ adjusts to $y_{b}$, and thus it is 'supply that responds to demand. This gives robust support to the Keynesian notion of growth as primarily determined on the demand side, with BOP [balance-of-payments] equilibrium acting as a long-run constraint and productive capacity adapting endogenously when actual growth is above the natural rate of growth' (Lanzafame 2014, p. 833, emphasis added).

The use of the actual growth rate of output as the regressand in Razmi's individual country regression analyses makes it impossible to test which countries are, and which are not, balance-of-payments-constrained as in the traditional (Thirlwall) approach discussed above.

Consequently, the preferable approach to the testing of whether or not the growth of a country is balance-of-payments-constrained is still the original method using Thirlwall's law.

\section{THE IMPACT OF RELATIVE PRICES AND THIRLWALL'S LAW}

A sine qua non of the balance-of-payments-constrained growth model is that the rate of change of relative prices plays a quantitatively small role in the determination of the growth of exports and imports. The empirical evidence suggests that this is nearly always the case.

A recent comprehensive survey of estimates of the Marshall-Lerner condition found that 'the results of our analysis are clear: The M-L [Marshall-Lerner] condition does not [statistically] hold in a large fraction of cases in which it is claimed to do so' (Bahmani et al. 2013, p. 435). They also provided their own estimates and further concluded that 'those who draw on previous studies to support certain expected benefits from a currency depreciation should think twice before they rely too heavily on such estimates' (ibid., p. 439). Recall that even when the Marshall-Lerner condition is met, given the specification of the import and export demand functions discussed, it is necessary for the rate of change of relative prices to be continuous for it to affect the balance-of-payments-constrained growth rate. This is implausible. Even for relatively homogenous agricultural commodities the evidence that the Neoclassical law of one price holds is not convincing (Thursby et al. 1986; Ardeni 1989). 
There are now numerous estimations of Thirlwall's law (and other econometric estimations of export and import demand functions) that confirm the unimportance of relative prices for a wide range of countries. Recent studies include Lanzafame (2014), which has been discussed above. Christodoulopoulou and Tkačevs (2016) find this unimportance to be true for the euro area countries, using a variety of relative price measures. Romero and McCombie $(2016 ; 2018)$ also show this using export data for industries and quality-adjusted relative prices for a number of developed countries. As noted above, these three studies correct for any simultaneous equation bias.

There is the substantial research emanating from the European Central Bank's Research Competitiveness Network which has confirmed the overwhelming importance of non-price competitiveness in explaining changes in both cumulative export market shares and export performance. This analysis has become possible in recent years with the construction of large data sets with highly disaggregated international products and prices.

The approach, inter alia, is to construct two separate aggregate indices of trade prices using data at a high level of disaggregation. The first is the 'conventional' relative unit value (value per physical measure of goods such as tonnage), or conventional relative export price (RXP), and measures only price competitiveness. The second is the relative export price adjusted for quality and taste. It is "measure of price per unit of utility'. A comparison of the two indices reflects the contribution of non-price factors to changes in export prices (Benkovskis and Wörz 2015; see also Benkovskis and Wörz 2012; 2016).

The problem has been posed by Benkovskis and Wörz (2015) in their aptly titled paper, 'Cost competitiveness: a dangerous obsession'. They ask: 'How can we reconcile real effective exchange rate (REER) - and hence an apparent deterioration in cost competitiveness - with rising world market share - a clear sign of improved competitiveness?' (This is the Kaldor 1978 paradox.) They point out that many emerging market economies have increased their share of world markets with increasing relative prices, while other countries have lost global market share despite increasing cost competitiveness. They show that it is due to changes in non-price competitiveness. The first result that is in accordance with Allard's (2009) findings for four Central European economies, inter alia.

In the case of the US, for example, since about the year 2000 the conventional RXP has depreciated, but so also has the US market share. What accounts for this paradox? The answer, according to Benkovskis and Wörz (2015) is that the RXP, after it has been adjusted for quality, has increased markedly over this period, suggesting a decline in non-price competitiveness. The fall in the conventional real exchange rate has been more than offset by a decline in the relative (although not absolute) quality of US exports. Moreover, China, in particular, owes its export success to the substantial gains in its non-price competitiveness, and not to the increasing relative cheapness of its exports. This confirms the conclusions of both Pula and Santabárbara (2011) and $\mathrm{Fu}$ et al. (2012) using regression analysis.

This method quantifies and 'highlights the crucial importance of non-price competitiveness in assessing emerging countries' performance on external markets', as well as for the developed countries (Benkovskis and Wörz 2016, p. 706). It also demonstrates that the effect of non-price competitiveness differs from country to country.

Boggio and Barbieri (2017) find that the growth of export market shares of 33 countries are significantly determined by the levels of unit labour costs (ULCs),

7. Some studies break these down into further indices including changes in tastes. 
but not their growth rates. However, relative ULCs should have been used (that is, costs relative to those of a country's trading competitors). Moreover, the panel data estimation implausibly imposes the same value of the coefficient on both the developed and developing countries. When the level of per-capita GDP is introduced as a variable capturing technological capabilities, the coefficient of the ULC variable becomes insignificant, suggesting the importance of the former. However, Felipe and Kumar (2014) present sceptical reasons about the use of ULCs as a measure of cost competitiveness.

Overall, the evidence discussed above confirms the crucial importance of non-price competitiveness in determining trade flows, as originally emphasized by Thirlwall (1979).

\section{CONCLUDING COMMENTS}

The argument that the only thing that tests of Thirlwall's law are doing is estimating a tautology has been shown to be both theoretically and econometrically erroneous. This has been confirmed by a simulation analysis. This hare was set running in 1981 by McCombie, but who, as a result of an interchange with Thirlwall in 1981, subsequently changed his mind.

We have confirmed Thirlwall's view by showing that the test of the law is an econometric matter and this, by itself, is sufficient to show that the law is not a tautology. There is nothing, a priori, to stop the estimates of both the income elasticities and price elasticities being statistically insignificant. This would empirically refute the law and, of course, a tautology cannot be refuted.

We have further shown that Razmi's (2016) attempt to reformulate Thirlwall's law is not compelling, particularly as it includes both the demand-side and the supply-side variables at the same time in a single estimating equation.

The evidence of the importance of non-price competitiveness, emphasized by Thirlwall (1979) has also been confirmed by studies that adjust relative price changes to reflect quality changes. The latter play an important part in explaining a country's changes in its cumulative export shares. Generally, rates of changes in relative prices have little or no effect on the growth of exports and imports and the Marshall-Lerner conditions are usually not met. The balance-of-payments constraint is important in understanding why growth rates differ.

\section{REFERENCES}

Allard, C. (2009), 'Competitiveness in Central Europe: what has happened since EU accession?', IMF Working Paper, WP/09/121, International Monetary Fund.

Ardeni P.G. (1989), 'Does the law of one price really hold for commodity prices?', American Journal of Agricultural Economics, 71(3), 661-669.

Bahmani, M., H. Harvey and S.W. Hegerty (2013), 'Empirical tests of the Marshall-Lerner condition: a literature review', Journal of Economic Studies, 40(3), 411-443.

Benkovskis, K. and J. Wörz (2012), 'Evaluation of non-price competitiveness of exports from Central, Eastern and Southeastern European countries in the EU market', Bank of Latvia Working Paper 1/2012.

Benkovskis, K. and J. Wörz (2015), 'Cost competitiveness: a dangerous obsession', VOX CEPR Policy Portal, available at: http://voxeu.org/article/cost-competitiveness-obsession.

Benkovskis, K. and J. Wörz (2016), 'Non-price competitiveness of exports from emerging countries', Empirical Economics, 51(2), 707-735. 
Blecker, R.A. (2016), 'The debate over "Thirlwall's Law": balance-of-payments-constrained growth reconsidered', European Journal of Economics and Economic Policies: Intervention, 13(3), 275-290.

Boggio, L. and L. Barbieri (2017), 'International competitiveness in post-Keynesian growth theory: controversies and empirical evidence', Cambridge Journal of Economics, 41(1), 25-47.

Christodoulopoulou, S. and O. Tkačevs (2016), 'Measuring the effectiveness of cost and price competitiveness in external rebalancing of euro area countries: what do alternative HCIs tell us?', Empirica, 43(3), 487-531.

Clavijo Cortes, P.H. and J. Ros Bosch (2015), 'La ley de Thirlwall: una lectura critica', Investigación Económica, 74(292), 11-40.

Dornbusch, R. (1975), 'Exchange rates and fiscal policy in a popular model of international trade', American Economic Review, 65(5), 859-871.

Felipe, J. and U. Kumar (2014), 'Unit labor costs in the eurozone: the competitiveness debate again', Review of Keynesian Economics, 2(4), 490-507.

Frenkel, J.A. and M.L. Mussa (1985), 'Asset markets, exchange rates and the balance of payments', in R. Jones and B.P. Kenen (eds), Handbook of International Economics, vol. 2, Amsterdam: New Holland, pp. 679-747.

Fu, X., R. Kaplinsky and J. Zhang (2012), 'The impact of China on low and middle income countries' export prices in industrial-country markets', World Development, 40(8), 1483-1496.

Goldstein, M. and M.S. Khan (1978), 'The supply and demand for exports: a simultaneous approach', Review of Economics and Statistics, 60(4), 275-286.

Goldstein, M. and M.S. Khan (1985), 'Income and price effects in foreign trade', in P.B. Kenen and R.W. Jones (eds), Handbook of International Economics, vol. 2, Amsterdam: North Holland, pp. 1041-1105.

Goncalves, C.E. and M. Rodrigues (2017), 'Exchange rate misalignment and growth: a myth?', IMF Working Paper, 17/283.

Houthakker, H.S. and S.P. Magee (1969), 'Income and price elasticities in world trade', Review of Economics and Statistics, 51(2), 111-125.

Isard, P. (1995), Exchange Rate Economics, Cambridge, UK: Cambridge University Press.

Kaldor, N. (1970), 'The case for regional policies', Scottish Journal of Political Economy, 17(3), 337-348.

Kaldor, N. (1978), 'The effect of devaluations on trade in manufactures', in N. Kaldor (ed.), Further Essays on Applied Economics, London: Duckworth, pp. 99-116.

Lanzafame, M. (2014), 'The balance of payments-constrained growth rate and the natural rate of growth: new empirical evidence', Cambridge Journal of Economics, 38(4), 817-838.

Lavoie, M. (2014), Post-Keynesian Economics: New Foundations, Cheltenham, UK and Northampton, MA: Edward Elgar Publishing.

León-Ledesma, M. and A.P. Thirlwall, A.P. (2002), 'The endogeneity of the natural rate of growth', Cambridge Journal of Economics, 26(4), 441-459.

McCombie, J.S.L. (1981), 'Are international growth rates constrained by the balance of payments? A comment on Professor Thirlwall', Banca Nazionale del Lavoro Quarterly Review, 34(139), 455-458.

McCombie, J.S.L. (2011), 'Criticism and defences of the balance-of-payments constrained growth model: some old, some new', PSL Quarterly Review, 64(259), 353-392.

Pula, G. and D. Santabárbara (2011), 'Is China climbing up the quality ladder? Estimating cross country differences in product quality using Eurostat's COMEXT trade database', ECB Working Paper, No 1310, European Central Bank.

Razmi, A. (2016), 'Correctly analysing the balance-of-payments constraint on growth', Cambridge Journal of Economics, 40(6), 1581-1608.

Ribeiro, R.S.M., J.S.L. McCombie and G.T. Lima (2019), 'Does real exchange rate undervaluation really promote economic growth?', Structural Change and Economic Dynamics, available at: https://doi.org/10.1016/j.strueco.2019.02.005.

Rodrik, D. (2008), 'The real exchange rate and economic growth', Brookings Papers on Economic Activity, (2), 365-412. 
Romero, J.P. and J.S.L. McCombie (2016), 'The multi-sectoral Thirlwall's law: evidence from 14 developed European countries using product-level data', International Review of Applied Economics, 30(3), 301-325.

Romero, J.P. and J.S.L. McCombie (2018), 'Thirlwall's law and the specification of export and import functions', Metroeconomica, 69(2), 366-395.

Thirlwall, A.P. (1979), 'The balance of payments constraint as an explanation of international growth rate differences', Banca Nazionale del Lavoro Quarterly Review, 32(128), 45-53.

Thirlwall, A.P. (1981), 'Are international growth rates constrained by the balance of payments? A reply to Mr McCombie', Banca Nazionale del Lavoro Quarterly Review, 34(139), 458-459.

Thirlwall, A.P. (2011), 'Balance of payments constrained growth models: history and overview', PSL Quarterly Review, 64(259), 307-351.

Thursby, M.C., P.R. Johnson and T.J. Grennes (1986), 'The law of one price and the modelling of disaggregated trade flows', Economic Modelling, 3(4), 293-302.

Williamson, J. (1983), The Open Economy and the World Economy, New York: Basic Books.

Woodford, M. (2008), 'Comments on Dani Rodrik, "The real exchange rate and economic growth", Brookings Papers on Economic Activity, 2, 420-439. 